\title{
ESTIMACIÓN Y CARACTERÍSTICAS DE LA DURACIÓN DEL DESEMPLEO EN BOLIVIA
}

\section{Carlos Foronda y Andrea Alcaraz}

\section{RESUMEN}

La tasa de desempleo de una economía es considerada el indicador sintético más empleado para describir un mercado laboral; sin embargo, no proporciona información suficiente sobre la dinámica del mismo. El presente estudio ofrece un análisis complementario de la dinámica del mercado laboral a través de la estimación de la duración completa del desempleo y de una aproximación metodológica adecuada a la disponibilidad de información en Bolivia mediante el uso de modelos paramétricos y no paramétricos que permiten una descripción del comportamiento de la duración del desempleo en relación a las características sociodemográficas de la población. Los resultados muestran que es necesario corregir los sesgos en los datos disponibles ya que ocasionan una sobreestimación de la duración del desempleo. Para ello se empleó el método de Corak M. y Heisz A. [1]. En el país, durante los últimos años, la duración del desempleo ha sido relativamente baja, aunque existen grupos vulnerables que experimentan largos períodos de búsqueda de empleo, como son las mujeres y los mayores. También se explora la relación entre la duración del desempleo con la educación técnica y área geográfica. Finalmente, se identifica la necesidad de incluir la informalidad, el subempleo y otras variables en el análisis.

Palabras clave: Modelos de Supervivencia, Duración del Desempleo, Políticas Laborales, Métodos Semiparamétricos y No Paramétricos, Búsqueda de Empleo. 